\title{
Testing a Conceptual Lumped Model in Karst Area, Southwest China
}

\author{
Peng Shi, ${ }^{1,2}$ Mi Zhou, ${ }^{2}$ Simin Qu, ${ }^{2}$ Xi Chen, ${ }^{1,2}$ Xueyuan Qiao, \\ Zhicai Zhang, ${ }^{2}$ and Xinxin $\mathrm{Ma}^{2}$ \\ ${ }^{1}$ State Key Laboratory of Hydrology-Water Resources and Hydraulic Engineering, Hohai University, Nanjing 210098, China \\ ${ }^{2}$ College of Water Resources and Hydrology, Hohai University, Nanjing 210098, China
}

Correspondence should be addressed to Peng Shi; ship@hhu.edu.cn

Received 21 September 2013; Revised 10 November 2013; Accepted 19 November 2013

Academic Editor: Y. P. Li

Copyright (C) 2013 Peng Shi et al. This is an open access article distributed under the Creative Commons Attribution License, which permits unrestricted use, distribution, and reproduction in any medium, provided the original work is properly cited.

\begin{abstract}
Karst aquifers are known for their heterogeneous physical properties and irregular complex flow patterns which make it a challenge to describe the hydrological behavior and to quantitatively define the distribution of river flow components using hydrologic models. In this paper, a conceptual lumped hydrologic model, Xin'anjiang model (XAJ), was applied in Sancha River, which is a karst basin in southwest China, for the simulation of streamflow. The performance of XAJ model was evaluated based on the model's ability to reproduce the streamflow and baseflow. Percentage of bias (PBIAS), Nash-Sutcliffe efficiency (NSE), coefficient of determination $\left(R^{2}\right)$, and standard deviation (RSR) were calculated between the simulated and measured flow for both calibration and validation period. The low PBIAS and RSR ( $2.7 \%$ and 0.367 for calibration period, $1.3 \%$ and 0.376 for validation period) and the high NSE and $R^{2}$ (0.866 and 0.866 for calibration period, 0.858 and 0.860 for validation period) indicate that the model structure and parameters are of reasonable validity. Furthermore, streamflow was separated to baseflow and surface flow using the "baseflow programme," and the calculated results indicate that the model could also reproduce the response of baseflow in such karst system.
\end{abstract}

\section{Introduction}

Karst terrain accounts for about $15 \%$ of the world's land and is home for around 1 billion people [1]. Water from Karst terrain supports upwards of $25 \%$ of the current world population [2]. Guizhou Province has one of the largest, continuous karst areas in the world. About $73 \%$ of Guizhou is karst, and $17.42 \%$ of the karst landforms are developed on continuously pure limestone $[3,4]$. The importance of karst aquifers as a water resource has grown, as the population in this region continues to expand causing an increasing demand of water. However, Karst rocky desertification is a serious problem in this region, especially in limestone areas $[5,6]$. It is a process featured by the degradation of karst areas originally covered by soil and vegetation into rocky landscapes or lithological deserts with little soil or vegetation covering. As a result, modeling the response of karst aquifers and water storage in such systems becomes an important challenge and is an important step to estimate the sustainable yield of karst aquifers as well as to evaluate future climatic or anthropogenic impacts on the sustainability of groundwater resources in these systems. However, Karst aquifers are known for their heterogeneous physical properties and irregular complex flow patterns which make it a challenge to describe the hydrological behavior and to quantitatively define the distribution of river flow components using hydrologic models [7]. For reliable simulations, the used models require an adequate representation of hydrological systems, which is particularly true in karst regions. Both distributed and lumped hydrological models were used to simulate the hydrological processes in karst systems $[8,9]$. Distributed models provide spatially distributed information about groundwater heads and flow, including karst processes in different degrees of complexity [10]. However, the application of distributed models is hampered by the complexity and heterogeneity of karst systems and the lack or limitation of detailed and quantifiable information about the physical parameters (soil, vegetation, fractures, conduits, and swallow holes). On the other hand, lumped models are based on a set of mathematical equations that represent the transfer from 
input [11-15]. This has resulted in the use of lumped models in karst hydrology.

In karst hydrology, two mains types of lumped models are generally used to simulate the rainfall-discharge relationship:

(1) empirical models (also called "black box" models) that represent a completely unknown system, neither on the structure of the aquifer, nor on hydrodynamics parameters. This type of model aims to characterize the overall relationship between rainfall and discharge. Most of these models have been already applied to numerous karst systems [16-22];

(2) reservoir models that are developed with simple discharge equation between linked reservoirs. The use of reservoir models is a simple and classical way which is being explored with software packages such as GARDENIA [23] or VENSIM, which has been used in surface hydrology for some years [24] and presently is being tested on karst aquifers.

From a physical point of view, the hydrologic functioning of a karst system is driven by the typical hydrodynamic behavior of each compartment that can be classified according to three distinct zones: epikarst, infiltration zone, and saturated/phreatic zone [25]. However, the abovementioned "black box" models and reservoir-based models poorly rely on the physical properties of functioning of karst systems. Thus, Xinanjiang conceptual lumped models (LPM) were developed, not only for reproducing the dynamics of the catchment but also for understanding the relations between karst system and its geological and human environment for managing the resource.

Conceptual lumped models (LPM) are based on the conceptualization of the karst aquifer as a whole; that is, dependent variables are not a function of spatial position, and physical relationships are not considered explicitly but are represented in general terms through the conceptualization of the aquifer. Due to their simplicity, LPMs are particularly useful for the interpretation of data when it is neither possible nor justified to use distributed parameter models [26]. Albeit based on a simplified physical interpretation of the processes which transform inputs into outputs, Xin'anjiang conceptual lumped models are sufficient to help define the nature and behavior of the karst contribution to river flows and the impact of future change on karst water resources.

The Xin'anjiang model was developed on the basis of the analysis of data from the Xin'anjiang Reservoir located in the Zhejiang, China. It has been applied extensively in most humid regions in the south and east of China with warm climate and little snow for runoff simulation and water resources planning. It has been improved incrementally since it was proposed in 1973 [27-30]. The advantages of the Xin'anjiang model in this study are that it is based on a simplified physical interpretation of the processes which transform inputs into outputs, while all the model parameters have clear physical meanings. High accuracy alone is insufficient for our purposes. By the application of this model, the relations between parameter values and natural conditions will be found and it is valuable for extending and developing the model to meet with more miscellaneous surface conditions.
Based on the extensive field research, the hydrological features of karst catchments in southwest China can be described as below [31]. (1) Abundant precipitation serves as a principal source for soil water replenishment. Soil in karst regions, characterized by a strong permeability and coarse vegetation covering, usually has a depth of $20-50 \mathrm{~cm}$. Thus we hold the opinion that runoff from karst catchments in southwest China occurred as stored-full runoff process. (2) Generally, two processes, quick flow and slow flow, are apparent and control the characteristics of a karst flow hydrograph $[17,32]$. (3) The open conduit provides low resistance pathways for the subsurface flow, which often has more in common with surface water than with groundwater [33]. (4) The relationship between karst groundwater storage and discharge in southwest China can be regarded as linear system $[34,35]$. These hydrological features satisfy some assumptions of Xin'anjinag model. Thus, we hold the opinion that the conceptual lumped Xin'anjiang model can be applied for predicting the flood processes in such area.

In this paper, the main features of flood and the applicability of Xinanjiang model to such karst area in Southwest China are thoroughly analyzed through a successful case study and the possibility and difficulty to apply Xin'anjiang model in Karst area are pointed out. The main points explored in this paper are

(1) testing the application of Xin'anjiang model in Sancha River Valley,

(2) using precipitation, evapotranspiration and discharge data to calibrate model parameters,

(3) analyzing the hydrological behavior in karst area Southwest China.

\section{Methods and Materials}

2.1. Study Area. Guizhou Province in Southwest China is located in the east side of the Yunnan-Guizhou Plateau and covers about $17,600 \mathrm{~km}^{2}$. This region is dominated by subtropical wet monsoon climate. The mean annual temperature is $20^{\circ} \mathrm{C}$. The highest average monthly temperature is in July, and the lowest is in January. Annual precipitation is $1140 \mathrm{~mm}$, with a distinct summer wet season and a winter dry season. Average monthly humidity ranges from $74 \%$ to $78 \%$.

The Sancha River Valley (Figure 1), located in the northwest part of Guizhou Province, is a tributary of the Wujiang River with an area of $7264 \mathrm{~km}^{2}$ and an elevation of $200-$ $2010 \mathrm{~m}$ above sea level. The studied area has a subtropical monsoonal climate with an annual precipitation of $1000 \mathrm{~mm}$. Rainfall mainly occurs between May and October. The temperature of this area ranges from $-1^{\circ} \mathrm{C}$ to $28^{\circ} \mathrm{C}$, with an annual average of $14^{\circ} \mathrm{C}$. Sancha River is a typical mountain river of $325.6 \mathrm{~km}$ long. In Sancha River Valley, karst is well developed and the topography is marked by numerous abrupt ridges, fissures, channels, sink-holes, swallow-holes, and caverns. The dominant lithology in this catchment is the pure and thick limestone of the Guanling Formation of the Middle Triassic. The limestone has a less than $10^{\circ}$ dip angle. Soil, commonly $20-50 \mathrm{~cm}$ in thickness, occurs on most slopes. The soil 


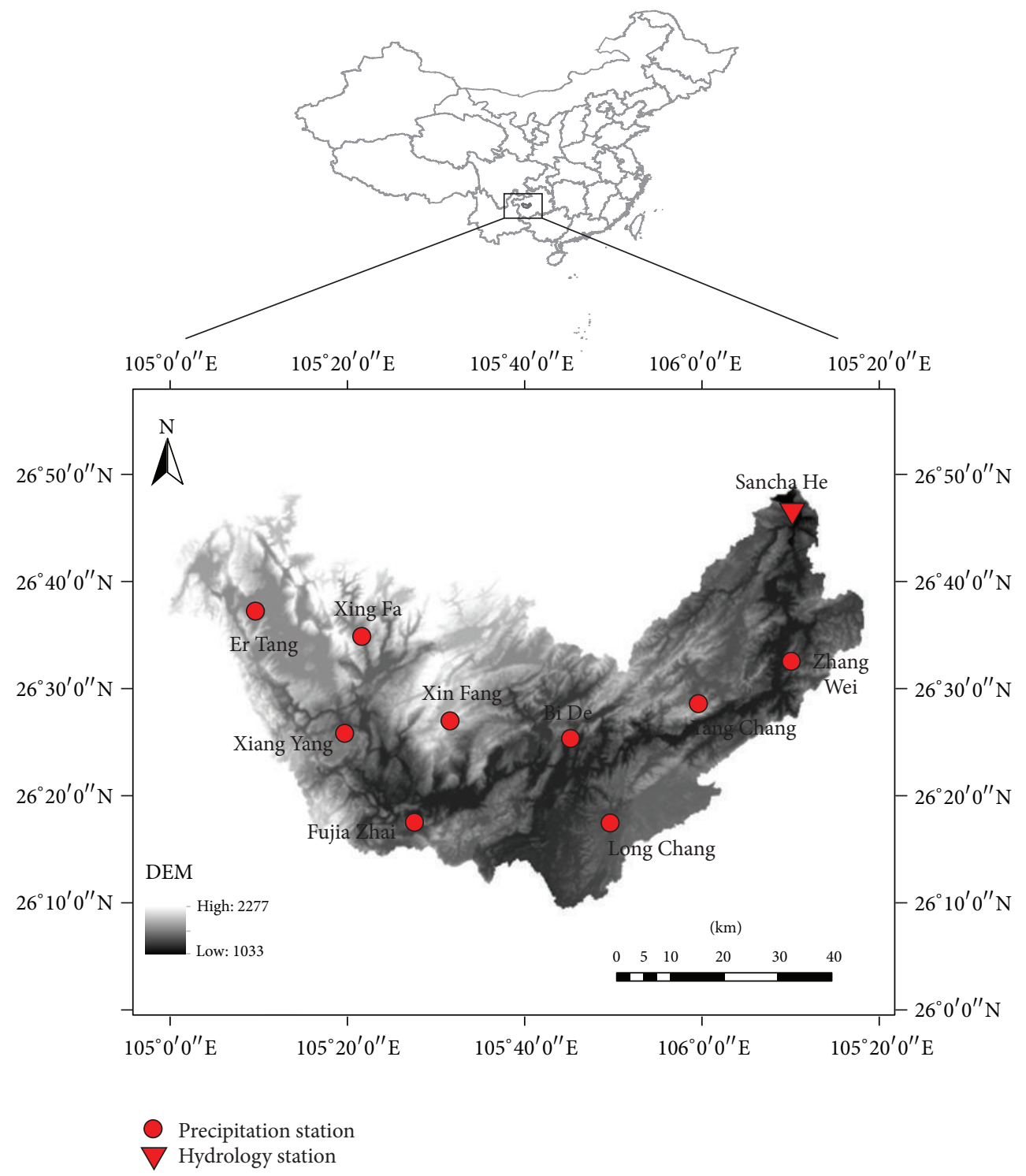

FIGURE 1: Location of Sancha River Valley.

has a clay content of $24-32.5 \%$ and a density of $1.13 \mathrm{~g} / \mathrm{cm}^{3}$. The organic matter content of the soil is $69.8-136.6 \mathrm{~g} / \mathrm{kg}$. The vegetation in the catchment is mainly broad-leaved deciduous shrubs and evergreens. The agriculture fields and pastureland are mainly located from mountain slope side to bottom. Crops commonly grown are corn, soybeans, and rape oil seed.

2.2. Description of Xin'anjiang (XAJ) Model. Xin'anjiang (XAJ) model is a conceptual hydrologic model developed by Zhao et al. [36] based on extensive observed data from the Xin'anjiang reservoir watershed. The XAJ model has been widely used in China for flood forecasting, hydrologic station network design, and water availability estimation [37]. XAJ has been used in all major river basins in China, including the Yellow River, Yangtze River, Huaihe River, and so forth.

According to the model structure, runoff was separated only into two components using the concept of a final, constant, infiltration rate. However, in 1980, the model was modified to represent the three components of surface runoff, subsurface flow, and groundwater flow. The karst water is also composed by surface runoff, rapid and slow ground flow $[38,39]$. The main feature of Xin'anjiang model is the concept of runoff formation on the depletion of storage, which means that runoff is not produced until the soil moisture content of the aeration zone reaches the field capacity, and thereafter runoff equals the rainfall excess without further loss. XAJ uses the runoff formation at natural storage mechanism to calculate runoff, making it valid only in humid and semihumid regions. The runoff-producing area is critical for calculating runoff. Runoff distribution is usually nonuniform across a region because the soil moisture deficit is heterogeneous. In order to accommodate the nonuniformity of the soil moisture deficit or the tension water capacity distribution, XAJ model adopted the storage capacity curve [36] to calculate total runoff. Shi et al. [40] proposed a method for calculating the 


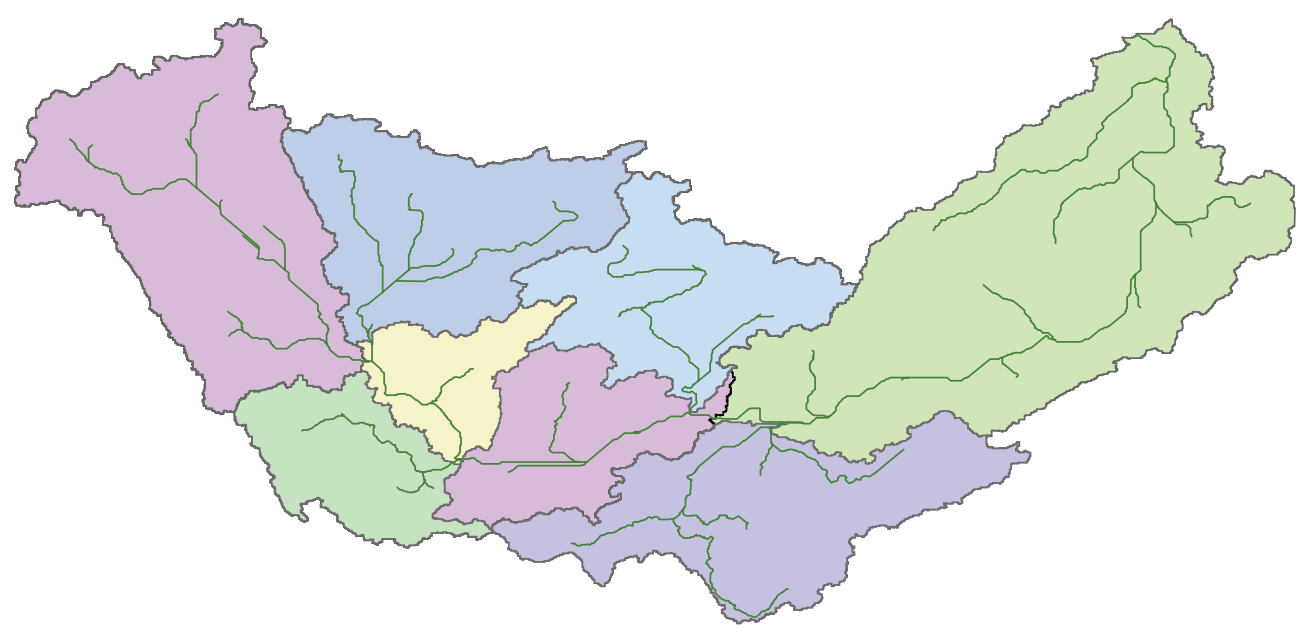

FIgURE 2: Subdivision of the study area.

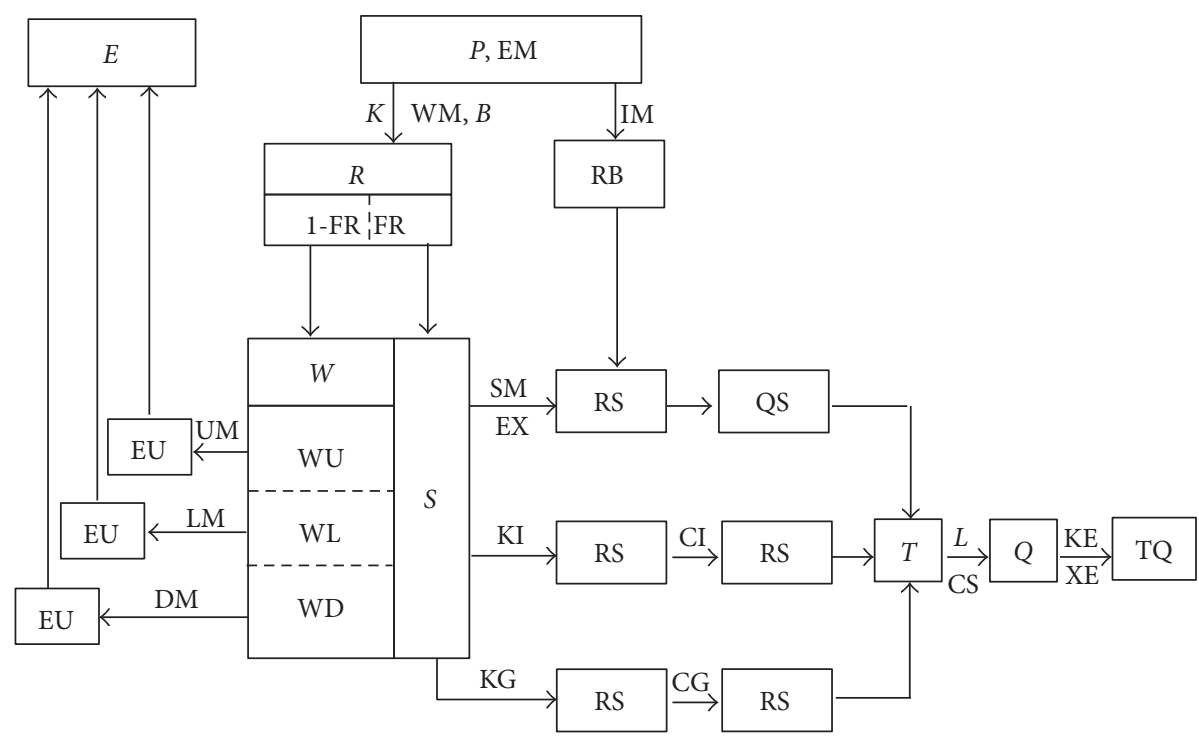

FIGURE 3: Flowchart for the Xin'anjiang model (adapted from Zhao, [37]).

water capacity from a topographic index. After calculating the total runoff, three components including surface runoff $Q_{\text {surf }}$, groundwater contribution $Q_{\mathrm{gw}}$, and contribution to lateral flow $Q_{\text {lat }}$ are separated [37]. By applying the Muskingum method to successive subreaches [41], flood routing from subbasin outlets to the total basin outlet is achieved.

XAJ divides a watershed into a set of subbasins (Figure 2) to capture the spatial variability of precipitation and the underlying surface. Instead of further delineating each subbasin into HRUs, XAJ uses the subbasin as the basic operation unit. XAJ requires precipitation and measured pan evaporation inputs. Outflow simulation from each sub-basin consists of four major parts: (1) the evapotranspiration which generates the deficit of the soil storage divided into upper, lower, and deep layers; (2) the runoff production which produces the runoff according to the rainfall and soil storage deficit; (3) the runoff separation which divides the total runoff into three components, surface runoff, subsurface runoff and groundwater, (4) the flow routing which transfers the local runoff to the outlet of each sub-basin forming the outflow of the sub-basin.

The flow chart of model calculation in each sub-basin is shown in Figure 3. All symbols inside the blocks are variables including inputs, outputs, state variables, and internal variables, while those outside the blocks are parameters. The inputs of the model are rainfall, $P$, and measured pan evaporation, EM. The outputs are the outlet discharge, $Q$, and the actual evapotranspiration, $E$. The function, methods, and corresponding parameters in every part (layer) are shown in Table $1 . K$ is the ratio of potential evapotranspiration to pan evaporation if pan evaporation measurements are used as references. WM and $B$ are two parameters describing the tension water distribution. WM, the areal mean tension water capacity, is the sum of UM in the upper layer, LM in the lower layer, and DM in the deeper layer. $B$ is the exponent of the tension water capacity distribution curve. IM is the 
TABLE 1: Function, methods, and parameters in Xin'anjiang model.

\begin{tabular}{lllllc}
\hline Layer & 1st & 2nd & 3rd & \multicolumn{2}{c}{ 4th } \\
\hline Function & Evapotranspiration & Runoff generation & $\begin{array}{l}\text { Water source } \\
\text { separation }\end{array}$ & Overland flow & River network flow \\
\hline Methods & $\begin{array}{l}\text { Three-layer } \\
\text { evaporation pattern }\end{array}$ & $\begin{array}{l}\text { Runoff yield at } \\
\text { natural storage }\end{array}$ & $\begin{array}{l}\text { Free water storage } \\
\text { reservoir model }\end{array}$ & Linear reservoir & Muskingum method \\
\hline Parameters & $\begin{array}{l}\text { KC, WUM, WLM, } \\
\text { and } C\end{array}$ & WM, $B$ & SM, EX, KI, and KG & CS, CI, CG & KE, XE \\
\hline
\end{tabular}

factor of impervious area. SM and EX are similar to WM and $B$, while they describe the free water capacity distribution. The areal mean of the free water capacity of the surface soil layer, SM, represents the maximum possible deficit of free water storage. Surface runoff is sensitive to the value of this parameter. EX is the exponent of the free water capacity curve. KG and KI are the outflow coefficients of the free water storage to groundwater and interflow. The sum of them determines the drainage rate from free water storage and their ratio determines the proportion going to interflow and groundwater flow, respectively. The daily recession constant of groundwater storage, CG, can be easily determined by the recession curve during the dry season. CS, the recession constant in the "lag and route" method for routing through the channel system within each sub-basin, is purely empirical. $\mathrm{KE}$ and XE are parameters of the Muskingum method which can be initially determined by hydraulic formulas. The more about physical meaning and value range of each parameter and the calculation are described in detail by [37].

The efficiency of the Xinanjiang model has been established by long use in China, and use of the model has also spread to other fields of application such as water resources estimation, design flood and field drainage, water project programming, hydrological station planning, water quality accounting, and so forth. However the uncertainty problem in hydrological model is inevitable, which covers three aspects of data, model structure and parameters. Firstly, during the modeling of hydrological processes the chief question is data problem, as well as the main reason of the uncertain problems. Making the fullest use of existing information, and introducing new data, especially combining remote sensing data with different scales of hydrological simulation, will significantly lower the uncertainty problem in Xinanjiang model. Secondly, enhance the fundamental research of hydrologic cycle. Based on the generalization and simplification of complex hydrology processes, the hydrological model should be improved continually during practical applications in order to promote the development of hydrological science. Thirdly, parameter is one of the key roles in analyzing model uncertainty problem. Usually, there is certain arbitrariness on parameters optimization based on traditional methods, and the results of parameters optimization in model are not the global optimal value which lack adequate stability [42]. The generalized likelihood uncertainty estimation (GLUE) methodology is an effective approach to study uncertainty of parameters. In the largest study of this kind, various computational approaches were investigated to analyze the impact of uncertainty on predictions of streamflow. SHU [43] employ GLUE to examine the uncertainty in Xin'anjiang model. The propagation of precipitation uncertainty through the Xin'anjiang model and the effect on the discharge simulation were analyzed quantitatively based on the fuzzy membership grade theory and the Monte Carlo method [44]. These studies are favorable for understanding Xin'anjiang model so as to provide valuable scientific information for future uncertainties research in hydrological modeling.

2.3. Data. The rainfall data used in this study are the daily rainfall data from ten permanent rain gauges of the Sancha River Valley in Guizhou and they were employed: Ertang, Xingfa, Xiangyang, Xinfang, Fujiazhai, Bide, Longchang, Yangchang, Zhangwei, and Sanchahe, with equal weighing coefficients of 0.1. There is one evaporation station (Bide) in the middle part of the catchment and a discharge station (Sanchahe) in the outlet of the catchment. All stations in the catchment have nearly complete records for water years 1991 to 2012, providing a unique dataset to apply the model for discharge simulation. The data were split into two independent subsets for model calibration and validation, respectively. The data from 1991 to 2005 were used for parameter calibration, and residual seven years (2006 to 2012) were used for model validation.

2.4. Model Calibration and Validation. Daily runoff data from January 1, 1991 to December 31, 2005 were used for calibration, and the remaining data from January 1, 2006 to December 31, 2012 were used to validate model performance.

In this study, we followed Santhi et al. [45] and Moriasi et al. [46] by using the following statistical evaluation tools: percent bias (PBIAS), coefficient of determination $\left(R^{2}\right)$, NashSutcliffe efficiency (NSE), and standard deviation (RSR). PBIAS is calculated as

$$
\text { PBIAS }=\left(\frac{\sum_{t=1}^{T}\left(Q_{s, t}-Q_{m, t}\right)}{\sum_{t=1}^{T} Q_{m, t}}\right) \times 100,
$$

where $Q_{s, t}$ is the model simulated value at time unit $t, Q_{m, t}$ is the observed data value at time unit $t$, and $t=1,2, \ldots, T$. PBIAS measures the average tendency of the simulated data to be larger or smaller than their observed counterparts. PBIAS values with small magnitude are preferred. Positive values indicate model overestimation bias, while negative values indicate underestimation [47]. 
TABLE 2: Parameters for Xin’anjiang model after calibration.

\begin{tabular}{lcccccccc}
\hline Parameter & $K$ & WM $(\mathrm{mm})$ & WUM $(\mathrm{mm})$ & WLM $(\mathrm{mm})$ & $B$ & $C$ & SM $(\mathrm{mm})$ & EX \\
\hline Value & 0.62 & 120.0 & 20.0 & 70.0 & 0.3 & 0.15 & 10 & 1.5 \\
\hline Parameter & KI & KG & CS & CI & CG & KE & XE \\
\hline Value & 0.3 & 0.4 & 0.55 & 0.875 & 0.98 & 1.0 & 0.46 & \\
\hline
\end{tabular}

The formula for calculating coefficient $R^{2}$ is

$$
R^{2}=\left\{\frac{\sum_{t=1}^{T}\left(Q_{m, t}-\bar{Q}_{m}\right)\left(Q_{s, t}-\bar{Q}_{s}\right)}{\left[\sum_{t=1}^{T}\left(Q_{m, t}-\bar{Q}_{m}\right)^{2}\right]^{0.5}\left[\sum_{t=1}^{T}\left(Q_{s, t}-\bar{Q}_{s}\right)^{2}\right]^{0.5}}\right\}^{2},
$$

where $\bar{Q}_{m}$ is mean observed data value for the entire evaluation time period and $\bar{Q}_{s}$ is the mean simulated data value for the entire evaluation time period. The other symbols have the same meaning defined above. $R^{2}$ is equal to the square of Pearson's product moment correlation coefficient [48]. It represents the proportion of total variance in the observed data that can be explained by the model. $R^{2}$ ranges between 0.0 and 1.0. Higher values mean better performance.

NSE is calculated as

$$
\mathrm{NSE}=1.0-\frac{\sum_{t=1}^{T}\left(Q_{m, t}-Q_{s, t}\right)^{2}}{\sum_{t=1}^{T}\left(Q_{m, t}-\bar{Q}_{m}\right)^{2}} .
$$

NSE indicates how well the plot of observed values versus simulated values fits the $1: 1$ line and ranges from $-\infty$ to 1 [49]. Larger NSE values are equivalent with better model performance.

The standard deviation (RSR) is calculated as:

$$
\operatorname{RSR}=\frac{\mathrm{RMSE}_{\mathrm{obs}}}{\mathrm{STDEV}_{\mathrm{obs}}}=\frac{\sqrt{\sum_{t=1}^{T}\left(Q_{m, t}-Q_{s, t}\right)^{2}}}{\sqrt{\sum_{t=1}^{T}\left(Q_{m, t}-\overline{Q_{s, t}}\right)^{2}}}
$$

2.5. Calibration Phase. The calibration process is as follows.

(1) Model parameters are assumed firstly using reasonable initial values according to their physical meaning and value range described in detail by Zhao [37]. $K$, UM, LM, and $C$ are evapotranspiration parameters. $\mathrm{WM}, B$, and IM are runoff production parameters. $\mathrm{SM}, \mathrm{EX}, \mathrm{KG}$, and $\mathrm{KI}$ are parameters of runoff separation. $\mathrm{CG}, \mathrm{CI}, \mathrm{CS}$, and $L$ are runoff concentration parameters. The output is more sensitive to $K, \mathrm{SM}$, $\mathrm{KG}, \mathrm{KI}, \mathrm{CG}, \mathrm{CS}$, and $L . K$, as an empirical coefficient transferring the pan evaporation to potential evapotranspiration, and is calibrated alone firstly. Pan evaporation in Bide evaporation station is used as reference in this study area. $C$ depends on the proportion of the basin area covered, and it can be adjusted after calibration of $K$. Parameters UM and LM are determined by experience. WM is the areal mean tension water capacity having components UM, LM,

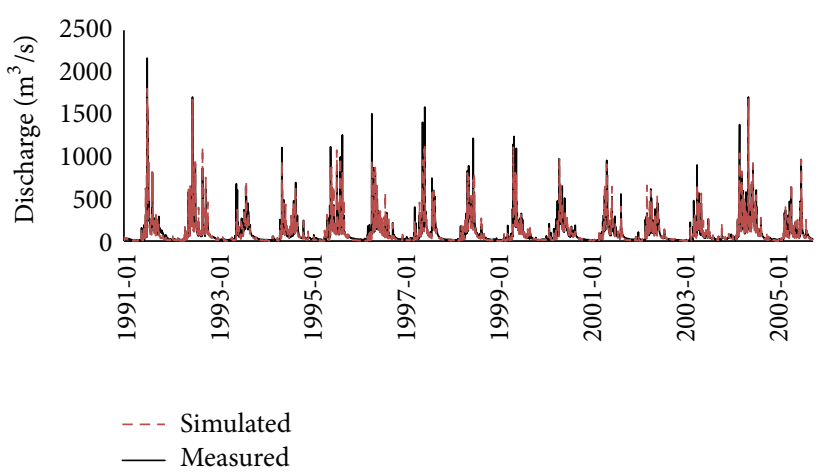

FIGURE 4: XAJ model simulation phase (1991 to 2005).

TABLE 3: The daily simulation results of the calibration and validation process.

\begin{tabular}{lcccc}
\hline & NSE & PBIAS & $R^{2}$ & RSR \\
\hline Calibration & 0.866 & 2.7 & 0.866 & 0.367 \\
Validation & 0.858 & 1.3 & 0.860 & 0.376 \\
\hline
\end{tabular}

and DM, and the value is provided large enough to ensure that the computed areal mean soil moisture content $W$ does not become negative. SM is the areal mean of the free water capacity of the surface soil layer. It may be approximately $10 \mathrm{~mm}$ or less for thin soils, increasing to $50 \mathrm{~mm}$ or more for thick surface soils. The best choice for the value of EX is between 1 and 1.5 and a fixed value $(0.7$ or 0.8$)$ is taken for the sum of KG and KI.

(2) Next, by comparing the simulated and observed hydrographs, a manual calibration is applied to refine model parameters by a trial-and-error method because the number of parameters is limited and the range is relatively short. Table 2 shows the set of model parameters obtained from the calibration phase (years from 1991 to 2005) for the Xin'anjiang model. The hydrograph obtained using the model for this period is compared to the measured hydrograph in Figure 4.

The daily simulation results of the calibration process are reported in Table 3. From the table, it can be seen that the percent bias (PBIAS), coefficient of determination $\left(R^{2}\right)$, NashSutcliffe efficiency (NSE), and standard deviation (RSR) for the calibration are $2.7,0.866,0.866$, and 0.367 . These results show that the calibrated parameters are realistic and reasonable. 


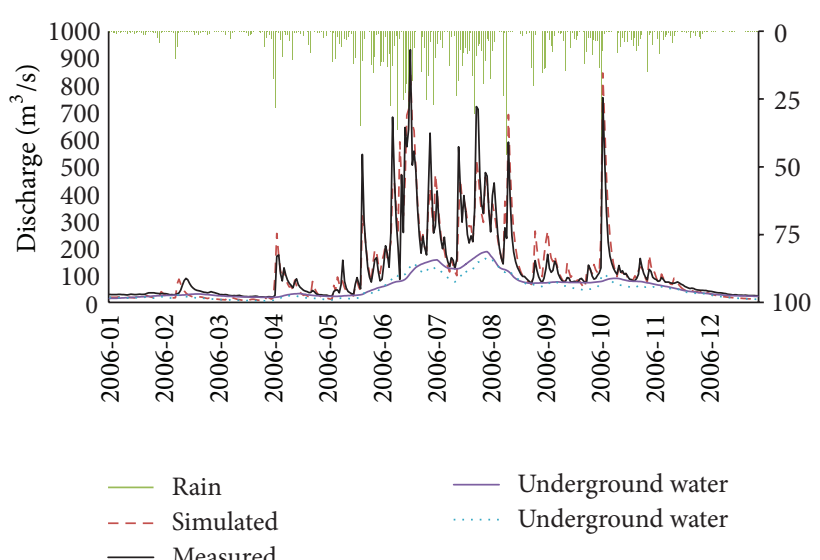

FIGURE 5: XAJ model validation phase (2006). Measured and simulated discharge, the groundwater runoff separated from the hydrograph and calculated by Xin'anjiang model, and catchment average rainfall time series.

2.6. Validation Phase. The hydrograph obtained using the model for the period 2006-2012 is compared to the measured hydrograph in Figures 5-11. The daily calculation results of the validation process are shown in Table 3 . From the table, it can be seen that the percent bias (PBIAS), coefficient of determination $\left(R^{2}\right)$, Nash-Sutcliffe efficiency (NSE), and standard deviation (RSR) for the validation are 1.3, 0.860, 0.858 , and 0.376. According to Moriasi et al. [46], the model performance is "very good."

\subsection{Model Response Analysis}

(1) Figures 5-11 present the observed and simulated total runoff and the groundwater runoff separated from the hydrograph and calculated by the model for study area. Both the calibration and validation graphs show very good similarity between observed and simulated total runoff. The goodness of fit of these graphs is measured by four statistical tests NSE, PBIAS, $R^{2}$, and RSR, which were described in Table 3. The results of these tests are given in Table 3 which indicate that the model is able to present reasonably well the runoff generated by rainfall events in study area. The groundwater runoff calculated by Xin'anjiang model also can be seen to reproduce the groundwater runoff separated from the hydrograph.

(2) Results of simulations show that good agreement in aspect of both timing and flow quantity exists between the calculated and observed maximum flood peak. For instance, maximum flood peaks occurred in June 2006 (Figure 5), June 2007 (Figure 6), June 2008 (Figure 7), July 2009 (Figure 8), June 2010 (Figure 9), June 2011 (Figure 10), and June 2012 (Figure 11).

(3) Hydrographs show the rapid confluence and precipitous fluctuation of flooding process following the intensive rainfall events when soil moisture content approach saturation. The response of runoff to rainfall

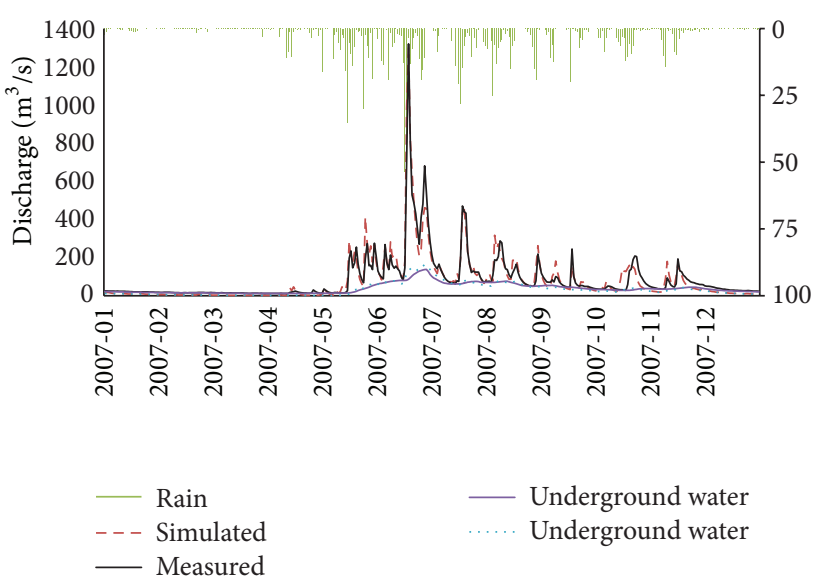

FIGURE 6: XAJ model validation phase (2007). Measured and simulated discharge, the groundwater runoff separated from the hydrograph and calculated by Xin'anjiang model, and catchment average rainfall time series.

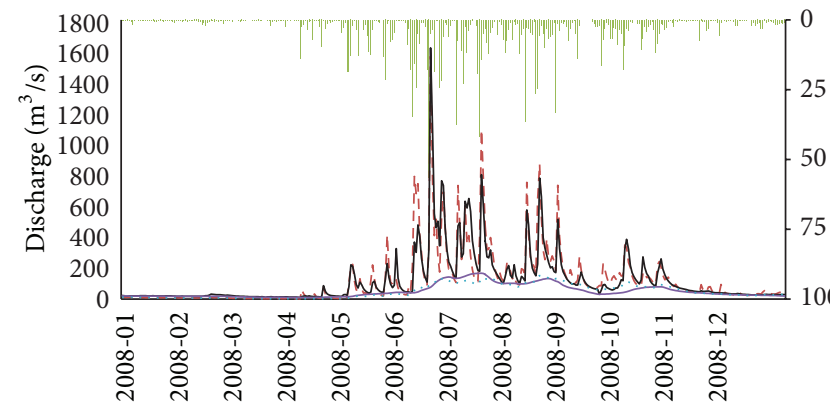

$$
\begin{array}{ll}
\text { - Rain } & \text { Underground water } \\
\text {-- } \text { Simulated } & \text { U.... Underground water } \\
\text { - Measured } &
\end{array}
$$

FIgURE 7: XAJ model validation phase (2008). Measured and simulated discharge, the groundwater runoff separated from the hydrograph and calculated by Xin'anjiang model, and catchment average rainfall time series.

implies a high sensitivity of runoff to the variation in rainfall quantity. They also show clearly the relatively steady groundwater runoff.

(4) However, further limitations in the rainfall-runoff relationship exist. A single precipitation time series cannot fully describe the dynamic of the runoff in karst area. It could be seen that after long dry periods, rainfall events that occurred could not generate any discharge peak and all the rainfall formed the groundwater runoff; for instance, the rainfall events occurred in January 2010 (Figure 11), while moderate rainfall events could generate strong flow peaks after a long wet period. A closer inspection of the response of karst catchments to rainfall events indicates that the vadose zone needs to reach a minimum volume for the possibility of the fast transfer to the outlet. On the contrary, when water content is high enough, it 


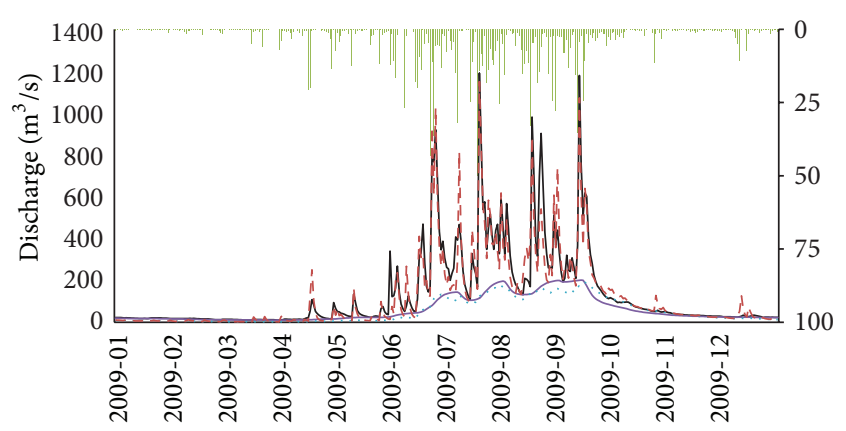

$\begin{array}{ll}\text { - Rain } & \text { Underground water } \\ --- \text { Simulated } & \text { Underground water } \\ \text { - Measured } & \end{array}$

Figure 8: XAJ model validation phase (2009). Measured and simulated discharge, the groundwater runoff separated from the hydrograph and calculated by Xin'anjiang model, and catchment average rainfall time series.

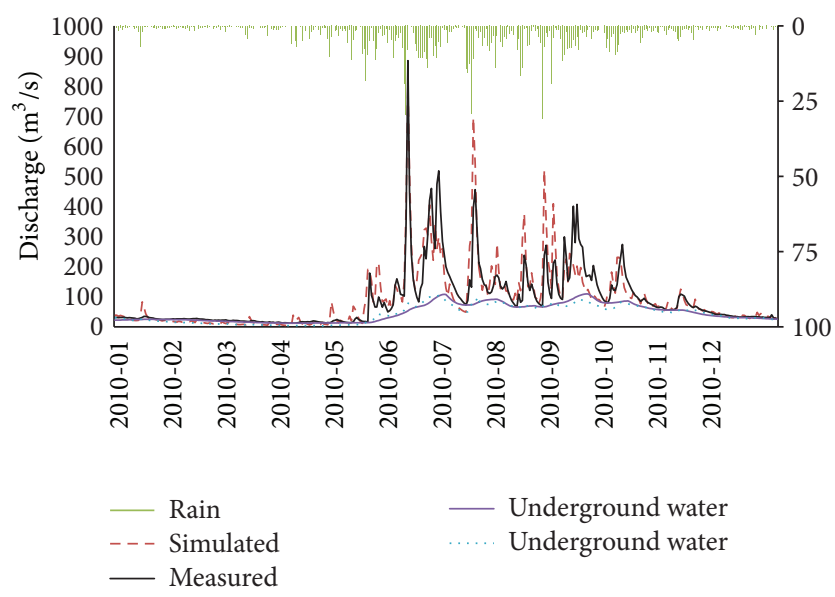

FIGURE 9: XAJ model validation phase (2010). Measured and simulated discharge, the groundwater runoff separated from the hydrograph and calculated by Xin'anjiang model, and catchment average rainfall time series.

activates the rapid transfer through the dissolutionwidened fractures towards the main outlet of the kast system. However, water does not flow necessarily towards one single outlet in karst hydrology. During high water periods, many temporary outlets may also discharge from the karst system [50]. This may generate a large increase in the flood peak discharge of the river, compared to the discharge attributed only to surface runoff processes [51-53].

(5) As mentioned above, the discharge peaks following a mild rainfall event in September 2010 (Figure 11) were overrated. The reason is that the runoff is strongly dependent on the initial state of karst system. As a result rainfall events occurring after long, dry periods and sparse, mild events are not able to generate any discharge peak or just generate small peak.

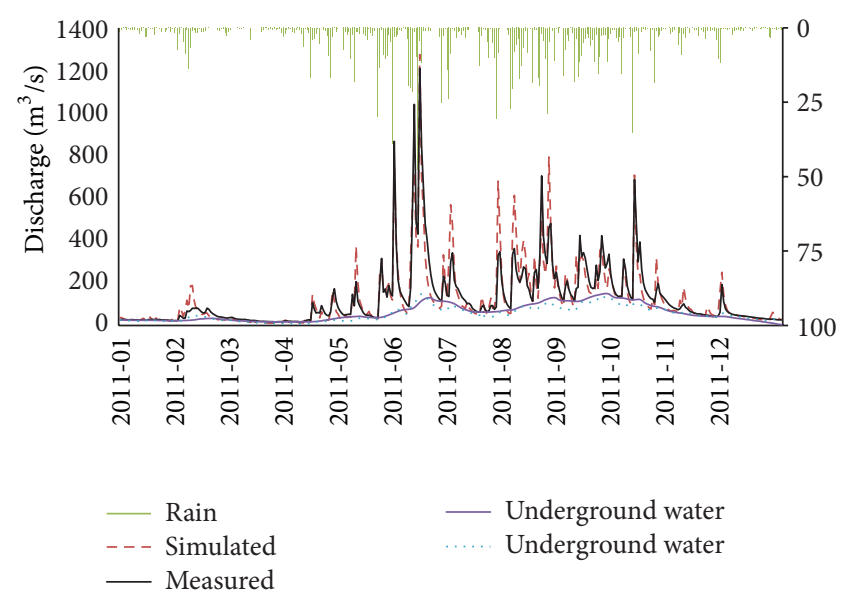

FIGURE 10: XAJ model validation phase (2011). Measured and simulated discharge, the groundwater runoff separated from the hydrograph and calculated by Xin'anjiang model, and catchment average rainfall time series.

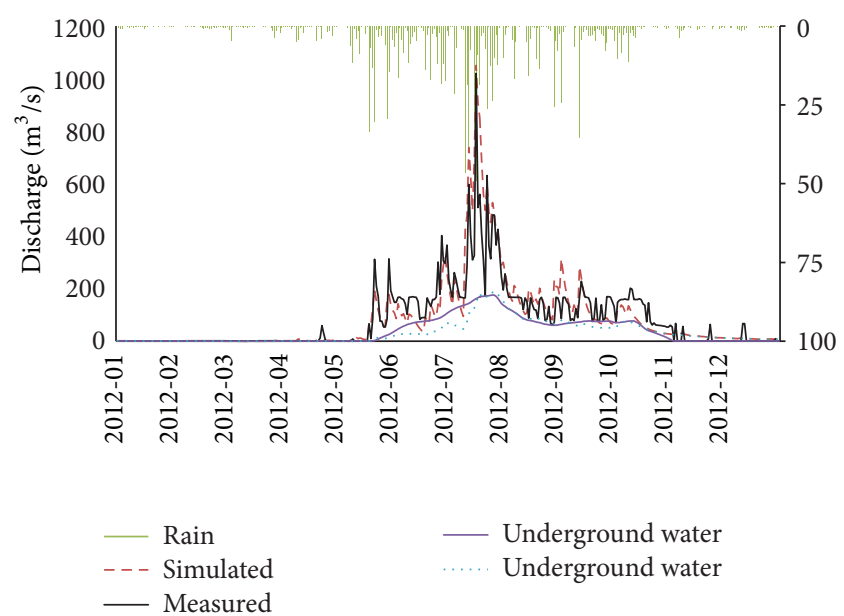

FIGURE 11: XAJ model validation phase (2012). Measured and simulated discharge, the groundwater runoff separated from the hydrograph and calculated by Xin'anjiang model, and catchment average rainfall time series.

(6) In low flow season, the baseflow could be reproduced accurately by the Xin'jiang model.

\section{Conclusion}

Xin'anjiang model has been applied for modeling hydrological response of Sancha River Valley (where a typical karst area). The applicability of Xinanjiang model in this area depends on the quality of data and the accuracy of the results obtained by this model. The obtained values of the model precision show that the results from Xin'anjiang model can be considered as a reliable estimation of the flow process in Sancha River Valley.

Hydrograph of karst basins has a feature of steep up-down limbs. Precipitation after a preceding drought that endures a long time generally produces quite small discharge. However, 
the peak flow, usually with a relatively high discharge rate, is observed shortly after the rainfall event, due to the fact that the system was already near-saturated before the rainwater drained into the main stream channel directly and quickly. Suitable parameters reflecting the hydrological and geomorphic condition are obtained by analyzing the hydrographic areas karst landform characteristics and karst features of flood in study area, and the simulation results indicate that Xin'anjiang model is reasonable and feasible to describe the hydrologic processes in this region.

The mode of recharge and transfer through the vadose zone (soil, epikarst, and infiltration zone) is a key variable in the development of a rainfall-discharge model. Structure of Xinanjiang model is generally based on a production function and a transfer function and has the advantages of keeping in memory the previous water storage in each aquifer and simulating the main steps of the aquifer functioning and all the model parameters have clear physical meanings for finding relations between parameter values and natural conditions. That is the reason why Xin'anjiang models were developed and used for simulating karst aquifer functioning. However, small-flow peaks following long, dry periods are still hard to be exactly simulated because of the sophisticated flow regimes of karst groundwater systems originated from the complexity of karst aquifers. Moreover, the application of the model for hydrological prediction in regions outside our study area requires more calibration data, and the uncertainty problem in hydrological model is inevitable. Nowadays, there are a variety of hydrological models described in the literature. However, all surface hydrological models, in general, reach their limit of applicability in complex hydrological environments. The choice of a suitable model depends on the availability of data and the goals that are to be achieved.

\section{Acknowledgments}

The first author thanks the following financial support: the National Natural Science Foundation of China (nos. 41001011/ 51190091/41101018/41371048/40930635); the Special Fund of State Key Laboratory of China (2009586412); the Ph.D. Programs Foundation of Ministry of Education, China (20090094120008); the Fundamental Research Funds for the Central Universities; and the Ground Project Granted by the Ministry of Education of China (20064). The paper was edited by Dr. Peng Jiang. Thanks are due to the editor and the anonymous reviewer for their constructive comments on the earlier paper that led to a great improvement of the paper.

\section{References}

[1] D. Yuan and G. Chai, The Science of Karst Environment, Chongqing Press, Chongqing, China, 1988.

[2] D. Ford and P. Williams, Karst Geomorphology and Hydrology, Unwin Hyman, London, UK, 1989.

[3] R. Li, S. Wang, D. Zhou et al., "The correlation between rock desertification and lithology in karst area of Guizhou," Acta Geographica Sinica, vol. 58, no. 2, pp. 314-320, 2003 (Chinese).

[4] Y. B. Li, S. J. Wang, and Z. F. Wei, "The spatial distribution of soil loss tolerance in carbonate area in Guizhou province," Earth and Environment, vol. 34, pp. 36-40, 2006 (Chinese).
[5] D. Yuan, "Rock desertification in the subtropical karst of south China," Zeitschrift für Geomorphologie, vol. 108, pp. 81-90, 1997.

[6] S. J. Wang, Q. M. Liu, and D. F. Zhang, "Karst rocky desertification in southwestern China: geomorphology, landuse, impact and rehabilitation," Land Degradation and Development, vol. 15, no. 2, pp. 115-121, 2004.

[7] M. Bakalowicz, "Karst groundwater: a challenge for new resources," Hydrogeology Journal, vol. 13, no. 1, pp. 148-160, 2005.

[8] A. J. Jakeman and G. M. Hornberger, "How much complexity is warranted in a rainfall-runoff model?" Water Resources Research, vol. 29, no. 8, pp. 2637-2649, 1993.

[9] M. Sauter, A. Kovács, T. Geyer, and G. Teutsch, "Modellierung der hydraulik von karstgrundwasserleitern-eine übersicht," Grundwasser, vol. 11, no. 3, pp. 143-156, 2006.

[10] N. Goldscheider and D. Drew, "Hydrogeologists," in Methods in Karst Hydrogeology, IAH-International Contributions to Hydrogeology, Taylor and Francis Group, London, UK, 1st edition, 2007.

[11] C. Butscher and P. Huggenberger, "Intrinsic vulnerability assessment in karst areas: a numerical modeling approach," Water Resource Research, vol. 44, no. 3, 2008.

[12] P. Fleury, V. Plagnes, and M. Bakalowicz, "Modelling of the functioning of karst aquifers with a reservoir model: application to fontaine de vaucluse (South of France)," Journal of Hydrology, vol. 345, no. 1-2, pp. 38-49, 2007.

[13] A. Hartmann, M. Kralik, F. Humer, J. Lange, and M. Weiler, "Identification of a karst system's intrinsic hydrodynamic parameters: upscaling from single springs to the whole aquifer," Environmental Earth Sciences, vol. 65, no. 8, pp. 2377-2389, 2012.

[14] P. Shi, M. Wu, X. Chen, Z. C. Zhang, and S. M. Qu, "A conceptual distribution hydrologic model for karst area in Southwest China," Tropical Geography, vol. 33, no. 5, pp. 570-574, 581, 2013 (Chinese).

[15] S. Tritz, V. Guinot, and H. Jourde, "Modelling the behaviour of a karst system catchment using non-linear hysteretic conceptual model," Journal of Hydrology, vol. 397, no. 3-4, pp. 250-262, 2011.

[16] V. Denić-Jukić and D. Jukić, "Composite transfer functions for karst aquifers," Journal of Hydrology, vol. 274, no. 1-4, pp. 80-94, 2003.

[17] D. Labat, R. Ababou, and A. Mangin, "Rainfall-runoff relations for karstic springs. Part I: convolution and spectral analyses," Journal of Hydrology, vol. 238, no. 3-4, pp. 123-148, 2000.

[18] D. Labat, R. Ababou, and A. Mangin, "Rainfall-runoff relations for karstic springs. Part II: continuous wavelet and discrete orthogonal multiresolution analyses," Journal of Hydrology, vol. 238, no. 3-4, pp. 149-178, 2000.

[19] D. Labat, A. Mangin, and R. Ababou, "Rainfall-runoff relations for karstic springs: multifractal analyses," Journal of Hydrology, vol. 256, no. 3-4, pp. 176-195, 2002.

[20] M. Larocque, A. Mangin, M. Razack, and O. Banton, "Contribution of correlation and spectral analyses to the regional study of a large karst aquifer (Charente, France)," Journal of Hydrology, vol. 205, no. 3-4, pp. 217-231, 1998.

[21] D. Jukić and V. Denić-Jukić, "Nonlinear kernel functions for karst aquifers," Journal of Hydrology, vol. 328, no. 1-2, pp. 360374, 2006.

[22] A. Rimmer and Y. Salingar, "Modelling precipitation-streamflowprocesses in karst basin: the case of the Jordan River sources, Israel," Journal of Hydrology, vol. 331, no. 3-4, pp. 524$542,2006$. 
[23] D. Thiery, "Forecast of changes in piezometric levels by a lumped hydrological model," Journal of Hydrology, vol. 97, no. 1-2, pp. 129-148, 1988.

[24] A. Hreiche, D. Mezher, C. Bocquillon, A. Dezetter, E. Servat, and W. Najem, "Parallel processing for a better understanding of equifinality in hydrological models," in Proceedings of the Integrated Assessment and Decision Support (IEMSS '02), vol. 1, Lugano, Switzerland, June 2002.

[25] A. Mangin, Contribution à l'étude hydrodynamique des aquifères karstique [Ph.D. thesis], University of Dijon, France, 1975.

[26] P. Maloszewski and A. Zuber, "Manual on lumped-parameter models used for the interpretation of environmental tracer data in groundwaters," in Use of Isotopes for Analyses of Flow and Transport Dynamics in Groundwater Systems, Y. Yurtsever, Ed., pp. 1-50, Vienna, Austria, 2002.

[27] Z. J. Li, X. G. Kong, and C. W. Zhang, "Improving Xin'anjiang model," Hydrology in China, no. 4, pp. 19-23, 1998 (Chinese).

[28] Z. J. Li, K. Zhang, and C. Yao, "Comparison of distributed geological models based on GIS technology and DEM," Journal of Hydraulic Engineering, vol. 37, no. 8, pp. 1022-1028, 2006 (Chinese).

[29] Z. J. Li, C. Yao, and Z. H. Wang, "Development and application of grid-based Xin'anjiang model," Journal of Hohai University, vol. 35, no. 2, pp. 131-134, 2007 (Chinese).

[30] L. L. Wang, Z. J. Li, and H. J. Bao, "Application of hydrological models based on DEM in the Yihe basin," Journal of Hydraulic Engineering, no. 10, pp. 417-422, 2007 (Chinese).

[31] Zhang Jianyun and Zhuang Yiling, "Study and application of hydrological model for karst catchments," Journal of Hohai University, vol. 16, no. 3, 1988.

[32] V. Denić-Jukić and D. Jukić, "Composite transfer functions for karst aquifers," Journal of Hydrology, vol. 274, no. 1-4, pp. 80-94, 2003.

[33] Y. Lizheng, "Distribution of subterranean rivers in South China," Carsologica Sinica, vol. 4, no. 1, pp. 92-100, 1985 (Chinese).

[34] S. J. Dreiss, "Linear kernels for karst aquifers," Water Resources Research, vol. 18, no. 4, pp. 865-876, 1982.

[35] D. M. Ristic, "Water regime of flooded poljes," Karst Hydrology and Water Resources, vol. 1, pp. 301-318, 1976.

[36] R. J. Zhao, Y. L. Zhuang, L. R. Fang, X. R. Liu, and Q. S. Zhang, "The Xinanjiang model," in Hydrological Forecasting, IAHS Publication no. 129, pp. 351-356, IAHS, Wallingford, UK, 1980.

[37] R. J. Zhao, “The Xinanjiang model applied in China," Journal of Hydrology, vol. 135, no. 1-4, pp. 371-381, 1992.

[38] Y. Q. Huang and J. C. Weixin, "Discussion of rapid flow and retarded flow in karst water system," Carsologica Sinica, vol. 5, no. 4, 1986.

[39] K. Torbarov, "Estimation of permeability and effective porosity in karst on the basis of recession curver analysis," in Karst Hydrology and Water Resources, WRP, 1976.

[40] P. Shi, X. F. Rui, S. M. Qu, and X. Chen, "Calculating storage capacity with topographic index," Advances in Water Science, vol. 19, no. 2, pp. 264-267, 2008.

[41] R. J. Zaho, "A non-linear system model for basin concentration," Journal of Hydrology, vol. 142, no. 1-4, pp. 477-482, 1993.

[42] J. F. Chen, W. C. Zhang, and B. Wu, "Multi-objective calibration with predictive uncertainty analysis for conceptual hydrological model," Bulletin of Soil and Water Conservation, vol. 28, no. 3, pp. 107-112, 2008 (Chinese).
[43] C. Shu, S. X. Liu, X. J. Mo, Z. M. Liang, and D. Dai, "Uncertainty analysis of Xinanjiang model parameter," Geographical Research, vol. 27, no. 2, pp. 343-352, 2008.

[44] W. Liu, L. L. Ren, X. U. Jing, and X. F. Liu, "Propagation of precipitation uncertainty through the Xinanjiang model," Water Resources Protection, vol. 25, no. 6, 2009.

[45] C. Santhi, J. G. Arnold, J. R. Williams, W. A. Dugas, R. Srinivasan, and L. M. Hauck, "Validation of the SWAT model on a large river basin with point and nonpoint sources," Journal of the American Water Resources Association, vol. 37, no. 5, pp. 1169$1188,2001$.

[46] D. N. Moriasi, J. G. Arnold, M. W. Van Liew, R. L. Bingner, R. D. Harmel, and T. L. Veith, "Model evaluation guidelines for systematic quantification of accuracy in watershed simulations," Transactions of the American Society of Agricultural and Biological Engineers, vol. 50, no. 3, pp. 885-900, 2007.

[47] H. V. Gupta, S. Sorooshian, and P. O. Yapo, "Status of automatic calibration for hydrologic models: comparison with multilevel expert calibration," Journal of Hydrologic Engineering, vol. 4, no. 2, pp. 135-143, 1999.

[48] D. R. Legates and G. J. McCabe Jr., "Evaluating the use of "goodness-of-fit" measures in hydrologic and hydroclimatic model validation," Water Resources Research, vol. 35, no. 1, pp. 233-241, 1999.

[49] J. E. Nash and J. V. Sutcliffe, "River flow forecasting through conceptual models part I-a discussion of principles," Journal of Hydrology, vol. 10, no. 3, pp. 282-290, 1970.

[50] D. Jukić and V. Denić-Jukić, "Groundwater balance estimation in karst by using a conceptual rainfall-runoff model," Journal of Hydrology, vol. 373, no. 3-4, pp. 302-315, 2009.

[51] H. Jourde, A. Roesch, V. Guinot, and V. Bailly-Comte, "Dynamics and contribution of karst groundwater to surface flow during Mediterranean flood," Environmental Geology, vol. 51, no. 5, pp. 725-730, 2007.

[52] V. Bailly-Comte, H. Jourde, A. Roesch, and S. Pistre, "Mediterranean flash flood transfer through karstic area," Environmental Geology, vol. 54, no. 3, pp. 605-614, 2008.

[53] V. Bailly-Comte, H. Jourde, and S. Pistre, "Conceptualization and classification of groundwater-surface water hydrodynamic interactions in karst watersheds: case of the karst watershed of the Coulazou River (Southern France)," Journal of Hydrology, vol. 376, no. 3-4, pp. 456-462, 2009. 


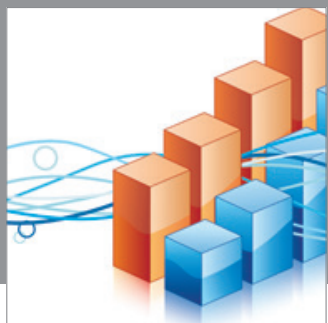

Advances in

Operations Research

mansans

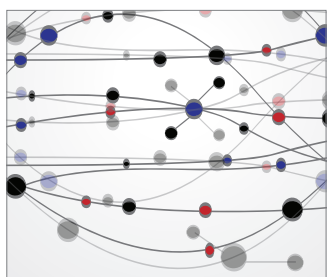

The Scientific World Journal
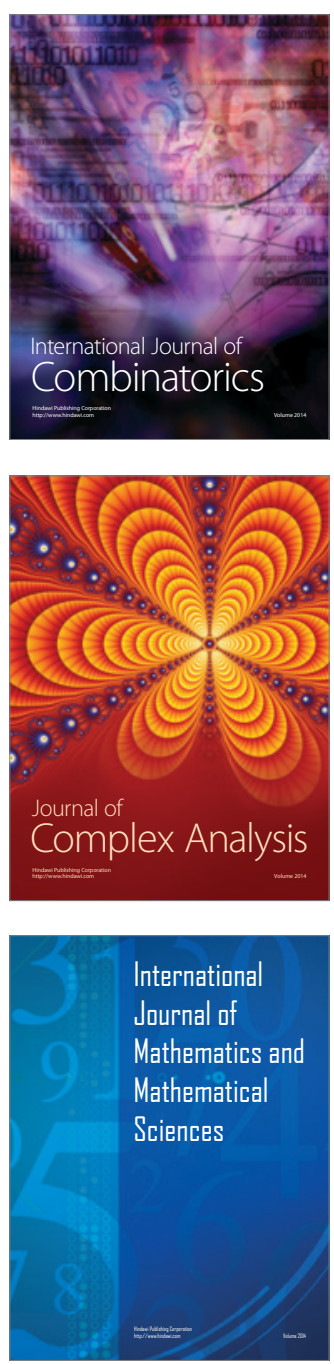
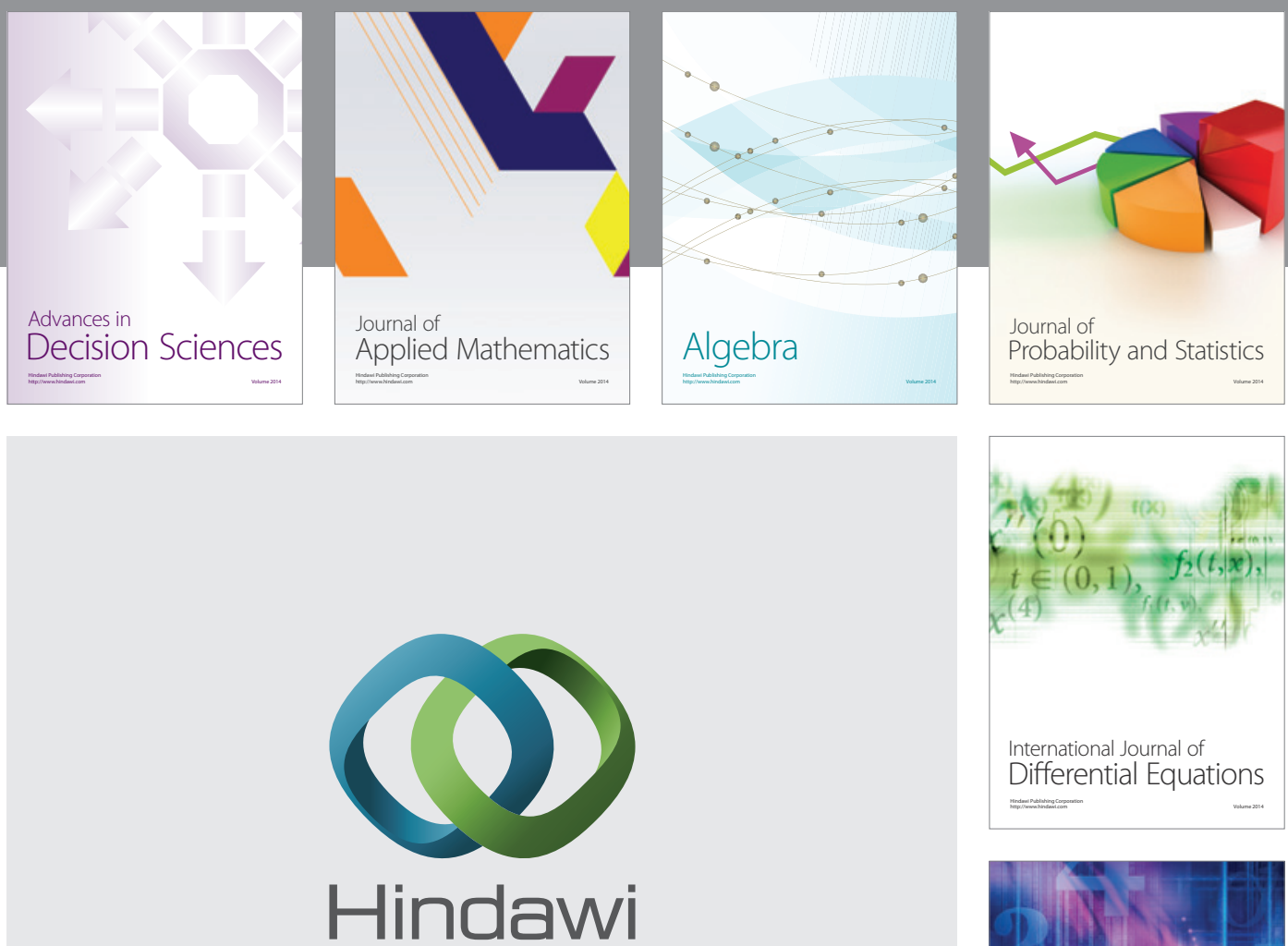

Submit your manuscripts at http://www.hindawi.com
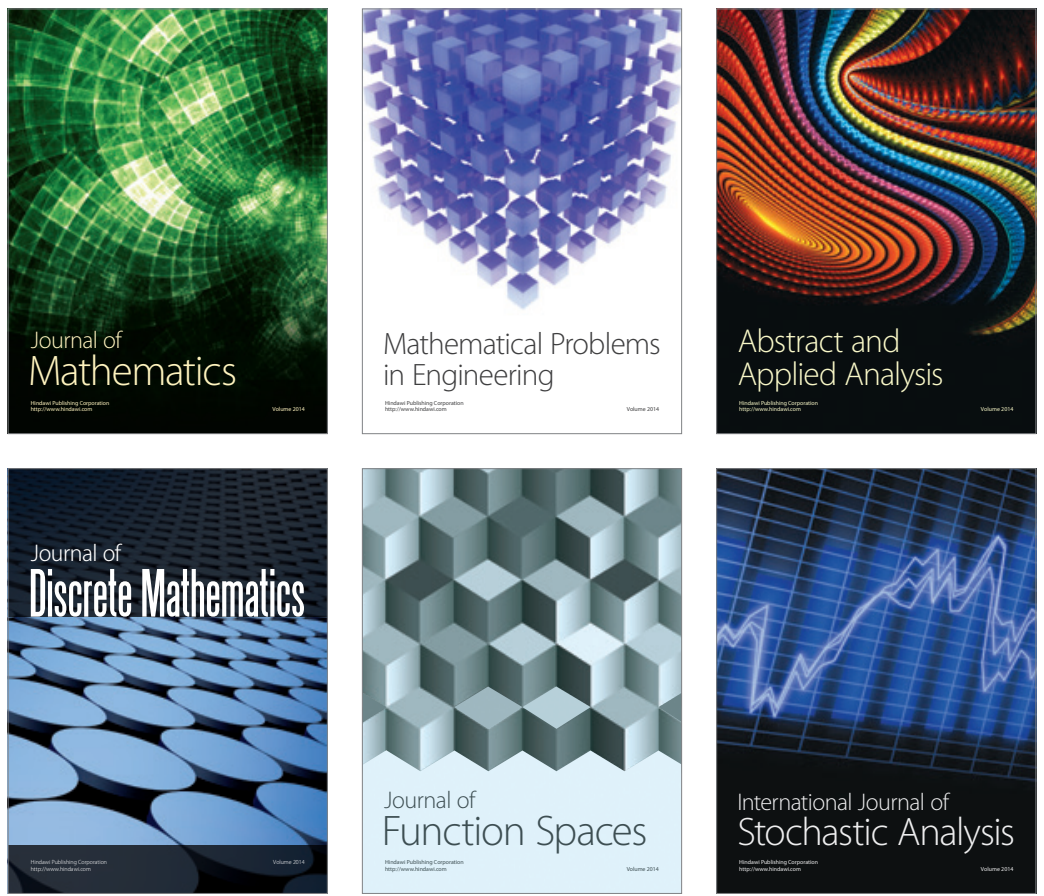

Journal of

Function Spaces

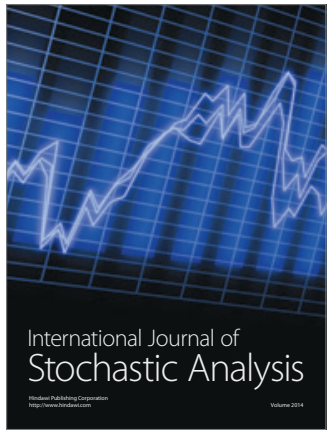

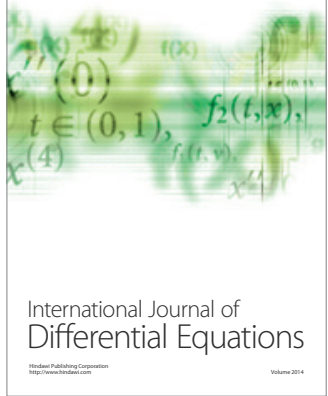
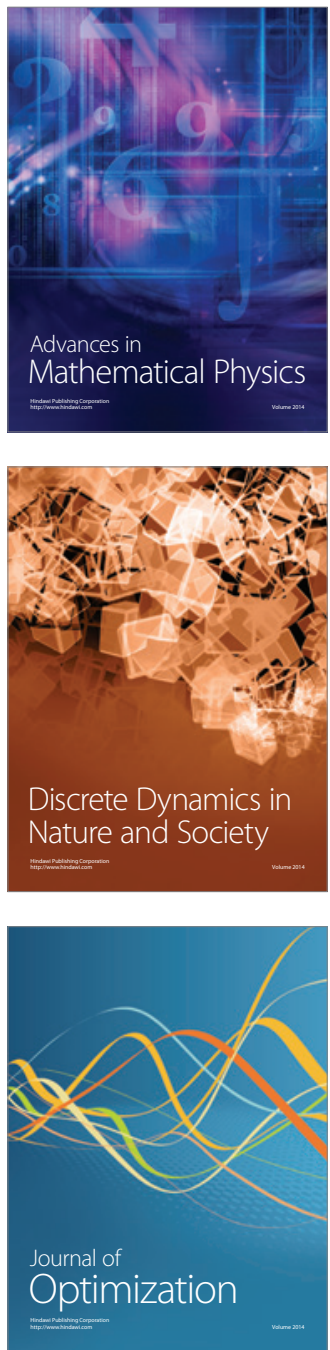